\title{
Novel cell-surface peptides specific to human oral squamous cell carcinoma using an $E$. coli peptide display library
}

\author{
NORIKO KAWAI ${ }^{1}$, JUNICHI ASAUMI ${ }^{1}$, JUN MURAKAMI ${ }^{1}$, TORU WAKASA ${ }^{1}$, \\ MASAHIRO KURODA ${ }^{2}$, MIKI HISATOMI ${ }^{1}$, TERUHISA UNETSUBO ${ }^{1}$, YUU MAKI ${ }^{1}$, \\ HIDENOBU MATSUZAKI ${ }^{1}$, YOSHINONU YANAGI ${ }^{1}$ and HIRONOBU KONOUCHI ${ }^{1}$ \\ ${ }^{1}$ Department of Oral and Maxillofacial Radiology, Field of Tumor Biology; \\ Departments of ${ }^{2}$ Radiology, Okayama University, Graduate School of Medicine, \\ Dentistry, and Pharmaceutical Sciences, 2-5-1, Shikata-cho, Okayama 700-8525, Japan
}

Received November 24, 2006; Accepted January 26, 2007

\begin{abstract}
We attempted to find a specific antigen of oral squamous cell carcinoma (SCC) cells that could be safely applied to gene therapy in the conservative clinical treatment of oral cancer. We performed subtraction using normal human keratinocyte cells, followed by selection using four oral SCC cell lines. We isolated three clones from poorly differentiated SCC cells and four from well-differentiated SCC cells. These seven clones adsorbed to the oral SCC cells at rates 10-100 times those of normal human keratinocyte cells. The three clones from the poorly differentiated SCC cells showed the same peptide sequence (LAPRTHP). Of the four clones from the well-differentiated SCC cells, three showed the same peptide sequence (FGTLPGT) and the fourth showed a different one (VTPNSTP). Each peptide sequence may recognize the material that exists specifically on the oral SCC cell cortex. We can expect applications not only for tumortargeting treatment using a gene therapy virus vector but also for diagnosis using, as a tumor marker, the peculiar SCC surface material that these peptides recognize.
\end{abstract}

\section{Introduction}

In the treatment of oral cancers, the preservation of aesthetic features and functions is critical. Conservative treatments for oral cancers usually consist of radiotherapy, chemotherapy, and thermotherapy. The great advantage of radiotherapy combined with chemotherapy and/or thermotherapy is that it allows the oral function and facial configuration of patients to be well preserved. However, it is now difficult to cure advanced

Correspondence to: Dr Junichi Asaumi, Department of Oral and Maxillofacial Radiology, Okayama University Graduate School of Medicine, Dentistry, and Pharmaceutical Sciences, 2-5-1, Shikata-cho, Okayama 700-8525, Japan

E-mail: asaumi@md.okayama-u.ac.jp

Key words: oral cancer, conservative treatment, gene therapy, squamous cell carcinoma cases with only conservative or surgical treatment. Therefore, conservative therapy for oral cancers should be further developed. However, few studies exist on the use of conservative combination therapy in treating oral cancers. We have also tried to establish a conservative treatments that combine radiotherapy, chemotherapy, thermotherapy, immunotherapy, and gene therapy in oral cancer (1-7). Those studies reported on the usefulness of wild-type p53-bearing adenovirus vectors in a combination of radiotherapy, thermotherapy, and thermoradiotherapy (therapy combining hyperthermia with radiotherapy) to treat cell lines of human oral squamous cell carcinoma (SCC) and salivary gland adenocarcinoma $(1,3-5)$. However, to clinically apply the wild-type p53-bearing adenovirus vector to the treatment of human oral cancer, several problems must be solved. The utility of gene delivery vectors is limited by the nonselective nature in which the vectors, either nonviral or viral, interact with the cell surface, resulting in the transduction of numerous cell types in addition to the target cells (8). Thus, the wild-type p53-bearing adenovirus vector is not specific to the cancer cell and is considered capable of damaging normal cells. The surface of a cell is a landscape of macromolecules that are specific to the function and state of the cell (9-11). The ligands for specific macromolecules can serve as targeting agents, assuming they have specificity for the cell type (12-14). Further development and general application of gene therapy will depend on the ability to target delivery vectors to tissues of interest and limit uptake by healthy tissues. Redirecting the vectors to other tissues has not yet been successful; therefore, targeting ligands are needed. Targeting may in some cases be done by an ex vivo procedure, but direct i.v. injection of organhoming complexes would be far less invasive and elaborate (12).

In the present study, we attempted to find a specific antigen for oral SCC cells that could be applied to gene therapy in clinical treatment.

\section{Materials and methods}

Cell lines and cultures. Four human oral SCC cell lines, HSC2, HSC3, HSC4, and SAS, were obtained from the Cell 
Resource Center for Biomedical Research Institute of Development, Aging, and Cancer, Tohoku University (Sendai, Japan). The normal human keratinocyte (HEK) cell line was obtained from Toyobo Bio Chemical Department (Tokyo, Japan). They were maintained in Dulbecco's modified Eagle's medium (MDEM) (Nissui Pharmaceutical Co., Ltd., Tokyo, Japan) and supplemented with $3 \mathrm{~g}$ glucose, $2 \mathrm{mM}$ glutamine, and $10 \%$ fetal bovine serum (FBS) (Hyclone Laboratories, Logan, UT, USA).

Phage libraries. Ph.-D.-7 phage display peptide library kits were obtained from New England BioLabs, Ipswich, MA, USA. Phages from the Ph.-D.-7 library displayed seven random amino acids, each flanked by cysteines, on the N-terminal of the pIII minor coat protein. The titer of the libraries varied from 0.5 to $2 \times 10^{13} \mathrm{pfu} / \mathrm{ml}$, and the complexity varied from $2.8 \times 10^{9}$ transformations.

Phage display. Phage libraries were amplified, purified, and titered according to the manufacturer's protocols. Biopanning (or affinity selection) is a purifying technique involving subtraction/selection cycles. Specifically, the target cells were plated into 96-well plates and cultured until 1 or 2 days after confluence; then $2 \times 10^{11}$ pfu of input phage library was used to pan confluent cultures of target cells (passages 2 to 4 ) in duplicate. Before biopanning, the growth medium was changed to $1 \mathrm{ml} \mathrm{DMEM}$ containing $1 \% \mathrm{BSA}$, and the plates of the target cells were incubated at $4^{\circ} \mathrm{C}$ for $15 \mathrm{~min}$.

First, we biopanned the HEK cells for three rounds (subtraction cycle) and made a culture of the phage library with HEK cells without binding specificity. For HEK cells, $2 \times 10^{11}$ pfu of precleared or stock phage library was incubated with cells for $1 \mathrm{~h}$ at $4^{\circ} \mathrm{C}$. Cells were washed 5 times in icecold $\mathrm{PBS} / 1 \% \mathrm{BSA}$ for $5 \mathrm{~min}$ per wash. Weakly associated phages were eluted in $1 \mathrm{ml} 0.2 \mathrm{~mol} / \mathrm{l}$ glycine $(\mathrm{pH} 2.2)$ for $10 \mathrm{~min}$ on ice, followed by neutralization with $200 \mu 1$ Tris$\mathrm{HCl}$ ( $\mathrm{pH}$ 8.0). High-affinity phages (tightly bound phages) were isolated by lysing the cells in $1 \mathrm{ml}$ of $30 \mathrm{~m} \mathrm{~mol} / 1$ Tris$\mathrm{HCl} / 1 \mathrm{~m} \mathrm{~mol} / \mathrm{l}$ EDTA ( $\mathrm{pH}$ 8.0) for $1 \mathrm{~h}$ on ice. Each well was filled completely with blocking buffer $[0.1 \mathrm{M} \mathrm{NaHCO}$ ( $\mathrm{pH} 8.6$ ), $0.5 \% \mathrm{BSA}, 0.02 \% \mathrm{NaN}_{3}$ ], then incubated for $1 \mathrm{~h}$ at $4^{\circ} \mathrm{C}$. After the buffer was discarded, each well was washed 6 times with PBS. The subtracted phage supernatant was skimmed onto each well and rocked gently for $60 \mathrm{~min}$ at room temperature. The subtracted supernatant was recovered and used to resuspend other subtraction cells. This subtraction cycle was repeated 3 times in total.

Next, we biopanned the four human oral SCC cell lines for three rounds (selection cycle) using well- and poorly differentiated SCC cells, respectively, and in succession. The HSC2 and HSC4 cells originated from well-differentiated oral SCC cells. The HSC3 and SAS cells originated from poorly differentiated SCC cells. Each well containing four SCC cells was filled completely with blocking buffer then incubated for $1 \mathrm{~h}$ at $4^{\circ} \mathrm{C}$. After the buffer was discarded, each well was washed 6 times with PBS. The subtracted phage supernatant was skimmed onto each well and rocked gently for $60 \mathrm{~min}$ at room temperature. The plates were washed for 10 min with PBS. To block nonspecific binding, each well was filled with $0.2 \mathrm{M}$ glycine- $\mathrm{HCl}(\mathrm{pH} 2.2), 1 \mathrm{mg} / \mathrm{ml} \mathrm{BSA}$, and was rocked gently for no more than $10 \mathrm{~min}$. Then each well was neutralized with $15 \mu \mathrm{l}$ of $1 \mathrm{M}$ Tris- $\mathrm{HCl}$ (pH 9.1). To obtain the cell-surface antigen specific to the well-differentiated SCC cells, the subtracted phage supernatant was reacted first to the HSC2 cells, and then to the HSC4 cells. In a similar way, to obtain the cell-surface antigen specific to the poorly differentiated SCC cells, the subtracted phage supernatant was reacted first to the SAS cells, and then to HSC3 cells. Cell debris was removed and the supernatant was restored. Phages were amplified and titered between each round to ensure 10 MOI per titer of the target cells.

Plaque amplification. After completion of biopanning, Escherichia coli (E. coli) ER2738 was infected with the resulting phages and plated, and individual plaques were picked, amplified, and sequenced. The E. coli ER2738 strain was cultured in LB medium overnight. The subtracted/selected phage supernatants were titered on LB/IPTG/X gel plates. The plaques from this titering could be used for sequencing. Using a sterile wooden stick, blue plaques were stabbed and transferred to the tubes containing ER2738 culture. A total of 40 clones were gathered, 20 clones of well-differentiated SCC cells and 20 clones of poorly differentiated SCC cells, and then they were amplified with the LB medium, a titration stripes lingua. Afterwards, peculiar phages were gathered or an adsorption bioassay was performed. Tubes were incubated at $37^{\circ} \mathrm{C}$ with shaking for $4.5 \mathrm{~h}$. The cultures were centrifuged, and the upper $80 \%$ of the supernatants were stored as the amplified phage stock.

Reconfirmation of phage clone specifity. Cell debris was removed and the supernatant recovered. Phages were amplified and titered between each round to ensure that $10^{9} \mathrm{pfu}$ of input phages was used at the start of each successive round. After completion of biopanning, E. coli ER2738 was infected with the resulting phages and plated, and individual plaques were picked, amplified, and sequenced. For further binding studies, high-titer homogeneous populations of each phage were prepared. Briefly, $1 \times 10^{7}$ pfu of each phage was biopanned on SCC and HEK cells for $30 \mathrm{~min}$ at $4^{\circ} \mathrm{C}$. Unbound phages were removed by stringent washing, and the resulting cellassociated phages were titered. The percentage recovery was calculated for each cell type with a peptideless phage to allow for background binding. In the four kinds of oral SCC and HEK cells, the selection was performed by gradually changing the density of the phage liquid of each of the 40 clones. The collected phage was infected with $E$. coli, of plaque formations were counted, and the percentage of adsorbed phages under the same density was calculated.

\section{Results}

In the 40 clones, the phages that were adsorbed to the oral SCC cells at a rate 10-100 times the rate of HEK cells included three clones from the poorly differentiated SCC cells and four from the well-differentiated SCC cells. The peptide sequence of the adsorption parts in the SCC of each of these seven clones was analyzed with a sequencer. All three phage clones from the poorly differentiated SCC cells showed the same DNA base sequence (Type I). The DNA base sequence 


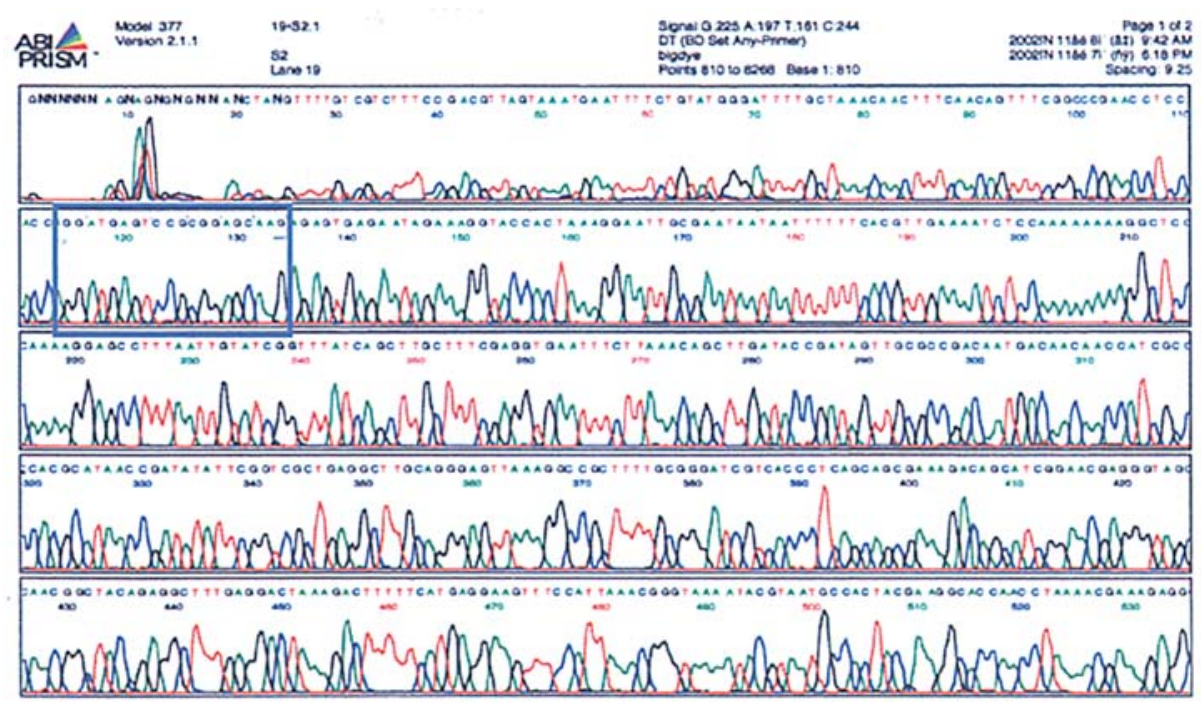

Figure 1. Type I. All three phage clones from the poorly differentiated SCC cells showed the same DNA base sequence. The DNA base sequence of Type I was AGG ATG AGT CCG CGG AGC AAG.

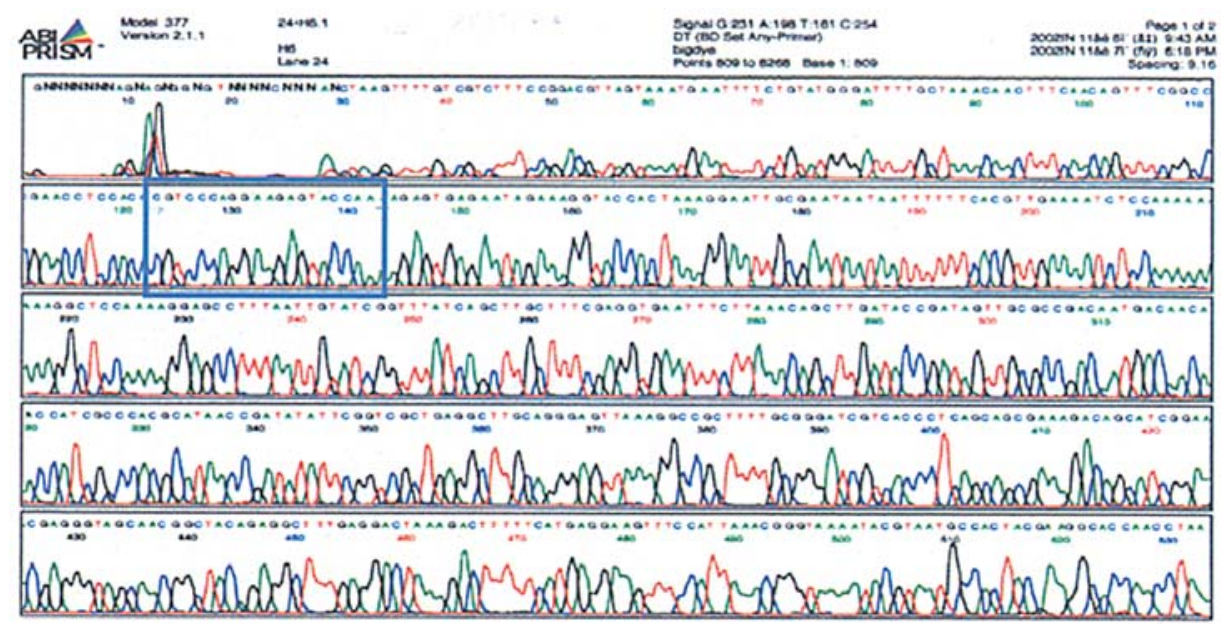

Figure 2. Type II. Of the four clones from the well-differentiated SCC cells, three had the same sequence. The DNA base sequence of Type II was AGG ATG AGT CCG CGG AGC AAG.

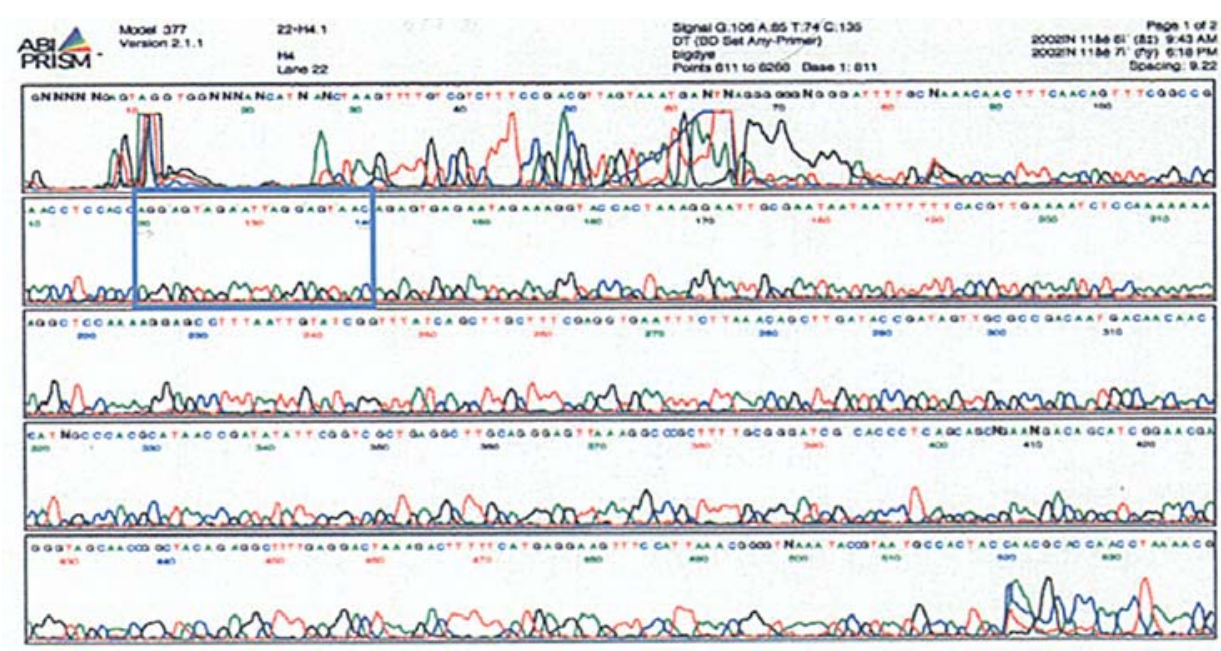

Figure 3. Type III. Of the four clones from the well-differentiated SCC cells, one showed a different sequence. The DNA base sequence of Type III was AGG ATG AGT CCG CGG AGC AAG. 
of Type I was 'AGG ATG AGT CCG CGG AGC AAG' (Fig. 1). Of the four clones from the well-differentiated SCC cells, three were the same sequence (Type II) and one had a different sequence (Type III) (Figs. 2 and 3). The DNA base sequence of Type II was AGG ATG AGT CCG CGG AGC AAG (Fig. 2). The DNA base sequence of Type III was AGG ATG AGT CCG CGG AGC AAG (Fig. 3).

\section{Discussion}

Gene therapy has the potential to play an important role in both immediate and indirect cancer treatment. It is necessary to introduce a gene exclusively into cancer cells in order to ensure its beneficial effect. It is not sufficient to infect cancer cells, though the method of infecting cells with a gene by a virus vector is often adopted (5). The discovery of materials that bind specifically to cancer cells, and that can thus be used in cell-specific gene or drug delivery, is crucial for improved cancer diagnosis and therapy (16-19).

In the present study, we attempted to find a specific antigen of oral SCC cells that could be safely applied to gene therapy in the conservative clinical treatment of oral cancer. We performed subtraction using normal cells (HEK cells), followed by a selection using four oral SCC cell lines. As a result, we isolated three clones from poorly differentiated SCC cells and four from well-differentiated SCC cells that adsorbed to the oral SCC cells at rates 10-100 times greater than those of HEK cells. The three clones from the poorly differentiated SCC cells had the same base sequence, AGG ATG AGT CCG CGG AGC AAG. Of the four clones obtained from the well-differentiated SCC cells, three had the same base sequence AGG ATG AGT CCG CGG AGC AAG, and the fourth had a different one, AGG ATG AGT CCG CGG AGC AAG.

First, the DNA base sequence is converted into the base sequence of complementary mRNA, and then the peptide sequence is decided by reading the mRNA from the counterdirection, as follows: The DNA base sequence of Type I is AGG ATG AGT CCG CGG AGC AAG. The complementary DNA base sequence is UCC UAC UCA GGC GCC UCG UUC. The peptide sequence is CUU(L) GCU(A) CCG(P) CGG(R) ACU(T) CAU(H) CCU(P) (LAPRTHP). The DNA base sequence of Type II is CGT CCC AGG AAG AGT ACC AAA. The complementary DNA base sequence is GCA GGG UCC UUC UCA UGG UUU. The peptide sequence is UUU(F) GGU(G) ACU(T) CUU(L) CCU(P) GGG(G) ACG(T) (FGTLPGT). The DNA base sequence of Type III is AGG AGT AGA ATT AGG AGT AAC. The complementary DNA base sequence is UCC UCA UCU UAA UCC UCA UUG. The peptide sequence is GUU(V) ACU(T) CCU(P) AAU(N) UCU(S) ACU(T) CCU(P) (VTPNSTP). As a result, we isolated three types of peptide sequences: LAPRTHP, FGTLPGT, and VTPNSTP. Each peptide sequence may recognize the material that exists specifically on the oral SCC cell cortex.

Before starting in vivo application of these peptides, we should confirm what kinds of specificity are included in the phage clones isolated in this study against many types of human culture cells, including SCC, using Phage ELISA. In case these peptides are applied to the diagnosis, we can apply the phage ELISA in vivo as we do for the diagnosis of SCC, and make antibodies to each peptide for the histopathological diagnosis. In addition, radionuclide techniques may allow us to diagnose SCC at an early stage by combining a suitable radioisotope with these monoclonal antibodies. When we apply these peptides to treatment, we can expect greater specific gene therapy for oral cancer by combining these SCC-specific phages with the p53 adenovirus vector. Thus, we can expect application not only to tumor-targeting treatments using gene therapy virus vectors but also to diagnosis using as a tumor marker the particular SCC surface material that these peptides recognize, although comparison in an in vivo experiment is also necessary.

\section{Acknowledgements}

Grant sponsors: Grant-in-Aid for Scientific Research on Priority Areas, Okayama University; and Grants-in-Aid (15591277, 16791240, and 17791458) for Scientific Research from the Ministry of Education, Science, Sports, and Culture of Japan.

\section{References}

1. Asaumi J, Murakami J and Kishi K: Recent findings elucidating the cellular basis of gene therapy in oral cancer. In: Gene Therapy in Cancer. Redberry GW (ed). Nova Science Publishers, New York, pp157-190, 2005.

2. Kawasaki S, Asaumi J, Shibuya K, Kuroda M and Hiraki Y: Recent aspects of elucidating the cellular basis of thermochemotherapy. In: Thermotherapy for Neoplasia, Inflammation, and Pain. Kosaka M, Sugahara T, Schmidt KL and Simon E (eds). Springer-Verlag, Tokyo, Berlin, pp424-432, 2001.

3. Higuchi Y, Asaumi J, Murakami J, Matsuzak H, Wakasa T, Inoue $\mathrm{T}$, et al: Thermoradiotherapy combined with adenoviral p53 gene therapy in head and neck squamous cell carcinoma cell lines. Oncol Rep 10: 415-420, 2003.

4. Asaumi J, Higuchi Y, Murakami J, Matsuzaki H, Wakasa T, Inoue $\mathrm{T}$, et al: Thermoradiotherapy combined with p53 gene therapy of human salivary gland adenocarcinoma cell line. Oncol Rep 10: 71-74, 2003.

5. Higuchi Y, Asaumi J, Murakami J, Wakasa T, Inoue T, Kuroda M, et al: Adenoviral p53 gene therapy in head and neck squamous cell carcinoma cell lines. Oncol Rep 9: 1233-1236, 2002.

6. Asaumi J, Higuchi Y, Murakami J, Kuroda M, Shibuya K, Konouchi $\mathrm{H}$, et al: Thermoradiotherapy in human head and neck squamous cell carcinoma cell lines. Int J Mol Med 10: 287-291, 2002.

7. Asaumi J, Higuchi Y, Matsuzaki H, Murakami J, Kawasaki S, Kuroda M, et al: Thermochemotherapy of a human salivary adenocarcinoma cell line. Oncol Rep 9: 365-369, 2002.

8. Nicklin SA, White SJ, Watkins SJ, Hawkins RE and Baker AH: Selective targeting of gene transfer to vascular endothelial cells by use of peptides isolated by phage display. Circulation 102: 231-237, 2000.

9. Sioud $M$ and Hansen MH: Profiling the immune response in patients with breast cancer by phage-displayed cDNA libraries. Eur J Immunol 31: 716-725, 2001.

10. Heitner T, Moor A, Garrison JL, Marks C, Hasan T and Marks JD: Selection of cell binding and internalizing epidermal growth factor receptor antibodies from a phage display library. J Immunol Methods 248: 17-30, 2001.

11. Nielsen UB and Marks JD: Internalizing antibodies and targeted cancer therapy: direct selection from phage display libraries. Pharm Sci Technol Today 3: 282-291, 2000.

12. Rasmussen UB, Schreiber V, Schultz H, Mischler F and Schughart K: Tumor cell-targeting by phage-displayed peptides. Cancer Gene Ther 9: 606-612, 2002.

13. Barry MA, Dower WJ and Johnston SA: Toward cell-targeting gene therapy vectors: selection of cell-binding peptides from random peptide-presenting phage libraries. Nat Med 2: 299-305, 1996. 
14. Brown KC: New approaches for cell-specific targeting: identification of cell-selective peptides from combinatorial libraries. Curr Opin Chem Biol 4: 16-21, 2000.

15. Oyama T, Sykes KF, Samli KN, Minna JD, Johnston SA and Brown KC: Isolation of lung tumor specific peptides from a random peptide library: generation of diagnostic and celltargeting reagents. Cancer Lett 202: 219-230, 2003.

16. Popkov M, Rader C and Barbas CF III: Isolation of human prostate cancer cell reactive antibodies using phage display technology. J Immunol Methods 291: 137-151, 2004.
17. Pollmann A, Kabisch H, Block A, Muller J and Hellwinkel OJ: Limited specificity of promoter constructs for gene therapy in osteosarcoma. Int J Mol Med 14: 737-742, 2004.

18. Landon LA and Deutscher SL: Combinatorial discovery of tumor targeting peptides using phage display. J Cell Biochem 90: 509-517, 2003. 